\title{
A possível mineração no bioma pampa e o escoamento de minérios pelo Porto de Rio Grande: disputas e impactos socioambientais
}

The possible mining in the pampa bioma and the discharging of ore by the Port of Rio Grande: disputes and socio- environmental impacts

\author{
Sérgio Botton Barcellos' \\ Caio Floriano dos Santos ${ }^{2}$ \\ Ricardo Gonçalves Severo ${ }^{3}$
}

\section{Resumo}

Os projetos em mineração estão em expansão no Brasil e também no Rio Grande do Sul (RS), incluindo a parte denominada "metade sul" ou "região da Campanha" no bioma Pampa. Atualmente, a possibilidade da instalação de uma mina na região está gerando impasses entre empresa, grupos locais e pesquisadores em debates e audiências públicas, levando também a contestações junto ao Ministério Público Federal (MPF) e a realização de diversas audiências nos municípios da "metade sul", inclusive no município de Rio Grande por onde vai escoar via Porto os minérios extraídos. Assim, por meio desse trabalho, o objetivo geral é trazer à tona quais os riscos socioambientais para o município de Rio Grande devido o escoamento dos concentrados de minério de chumbo, cobre, etc. a partir do exemplo de Antofagasta no Chile e Callao no Peru. A metodologia do trabalho é qualitativa e como procedimento metodológico foi realizada uma análise documental e de conteúdo sobre o EIA-RIMA do empreendimento minerário, bem como o acesso a estudos na plataforma Scielo e sites de notícias do Peru e do Chile que relataram casos de contaminação por chumbo e cobre. Ao discutir as relações de cooperação e conflito entre os atores nos debates públicos sobre a instalação desse empreendimento em mineração no bioma Pampa até o escoamento dos minérios pelo Porto de Rio Grande, buscaremos relacionar essa reflexão com a reconfiguração territorial do contexto rural brasileiro contemporâneo.

Palavras chave: Bioma Pampa; mineração; contaminação por chumbo; Porto; Rio Grande; conflitos socioambientais.

\footnotetext{
1 Professor Adjunto da Área de Sociologia da FURG e dos Programas de Pós-Graduação em Sociologia (UFPel) e Educação Ambiental (FURG). Doutor em Ciências Sociais do Desenvolvimento, Sociedade e Agricultura (CPDA) - UFRRJ. Atua nas temáticas da Sociologia ambiental, Sociologia rural, Estado e Desenvolvimento. E-mail: sergiobbarcellos@hotmail.com Cidade: Rio Grande.

2 Mestre em Planejamento Territorial e Desenvolvimento Socioambiental. Doutor em Educação Ambiental. Coordenador Adjunto do Observatório dos Conflitos do Extremo Sul do Brasil (FURG). Email: santoscaiof@gmail.com Cidade: Rio Grande.

3 Professor Adjunto da Área de Sociologia da FURG. Doutor em Ciências Sociais pela PUC - RS. Atua nas temáticas da Sociologia da Educação e Sociologia Política. E-mail: rg.severo@hotmail.com Cidade: Rio Grande.
} 
A Possível Mineração no Bioma Pampa e o Escoamento de Minérios pelo Porto de Rio Grande | Sérgio Botton Barcellos, Caio Floriano dos Santos \& Ricardo Gonçalves Severo

\begin{abstract}
Mining projects are expanding in Brazil and also in state of Rio Grande do Sul (RS), including the socalled "metade sul" or "Região da Campanha" in the "Bioma Pampa". Currently, the possibility of installing a mine in the region is generating impasses between companies, local groups and researchers in debates and public hearings, leading also to contestations with the Federal Public Ministry (MPF) and the holding of several hearings in the municipalities of the "half south ", including in the municipality of Rio Grande, through which the extracted ore flows via Porto. Thus, through this work, the general objective is to bring to light the socio-environmental risks for the municipality of Rio Grande due to the outflow of lead ore concentrates, copper, etc. from the example of Antofagasta in Chile and Callao in Peru. The methodology of the work is qualitative and as a methodological procedure a documentary and content analysis was done on the EIA-RIMA of the mining project, as well as the access to studies in the platform Scielo and news sites of Peru and Chile that reported cases of contamination for lead and copper. When discussing the relations of cooperation and conflict between the actors in the public debates about the installation of this mining enterprise in the Pampa biome to the ore flow through the Port of Rio Grande, we will try to relate this reflection with the territorial reconfiguration of the contemporary Brazilian rural context.
\end{abstract}

Keywords: Pampa Biome; Mining; Lead contamination; Seaport; Big River; Socio-environmental conflicts.

\title{
Introdução
}

As empresas mineradoras, que pleiteiam a expansão da sua atuação em diferentes partes do Brasil, também se encontram no Rio Grande do Sul (RS), atualmente visando se instalarem na denominada "metade sul" ou "região da Campanha" no bioma Pampa. Os empreendimentos que buscam se instalar nesta região têm como área de influência o conjunto de 28 municipios que compõem a bacia hidrográfica do Rio Camaquã até o seu deságue junto à lagoa dos Patos e no oceano Atlântico, nos municípios de Rio Grande e São José do Norte, extremo sul do Brasil. As atividades de mineração em questão incluem a extração de toneladas de minerais, como cobre, fosfato, prata, ouro, zinco e a extração de chumbo.

Analisando esta questão sob um contexto mais amplo, a maior parte dos recursos naturais extraídos, convertidos em commodities, são os minérios, que abastecem largamente o mercado externo, como a China e outros países da Ásia, além da Europa. Com relevância crescente na base econômica nacional, no ano 2000, por exemplo, os empreendimentos em mineração obtiveram crescimento de $8,2 \%$, sendo o setor que 
A Possível Mineração no Bioma Pampa e o Escoamento de Minérios pelo Porto de Rio Grande | Sérgio Botton Barcellos, Caio Floriano dos Santos \& Ricardo Gonçalves Severo

individualmente obteve o maior crescimento no Produto Interno Bruto (PIB) (BARRETO, 2001) ${ }^{4}$.

Os principais produtos minerais metálicos exportados pelo Brasil são minério de ferro, alumínio, ouro e cobre. O minério de ferro respondeu, em 2009, por 63,5\% das exportações brasileiras de minérios, que chegaram a quase US\$ 20 bilhões. Além disso, há um grande potencial geológico brasileiro não explorado e, como pode ser visto pelo Plano Nacional de Mineração 2030, é forte o estímulo à atividade de mineração. Segundo este Plano, há previsão de investimentos de $R \$ 350$ bilhões até 2030, destinados prioritariamente à Amazônia, mas também a outros locais. De todo modo, trata-se de um indicativo de que poderá se intensificar a atividade extrativa no país como um todo.

De acordo com a Revista Brasil Mineral (2018), em 2017 a atividade minerária no Brasil teve superávit de US\$23,4 bilhões, com crescimento de 30\% em relação a 2016 devido ao aumento das exportações e recuperação dos preços do minério de ferro. As exportações minerais totalizaram US\$ 46,4 bilhões e as importações em US\$ 23 bilhões. Ainda segundo o MME, em 2017 o setor mineral participou com 21,3\% das exportações brasileiras, que somaram US\$217,7 bilhões.

Além de inúmeros casos de fortes e extensos danos ambientais desta atividade na América Latina e na África, os impactos sociais em torno da mineração têm crescido em face das pressões por lucratividade, aliadas ao financiamento público. De acordo com o Observatório dos Conflitos em Mineração da América Latina $(\mathrm{OCMAL})^{5}$ registram-se 229 projetos de mineração implicados em conflitos socioambientais e 334 comunidades afetadas por esses projetos. No Brasil, de acordo com o Mapeamento dos Conflitos Ambientais, até o início do ano de 2017 cerca de 580 conflitos

\footnotetext{
4 O aumento da demanda de minério ocorreu pela expansão de fabricação de microeletrônicos e a realização de obras de infraestrutura e habitação nos países considerados emergentes nesse estágio global do capitalismo. Além disso, percebe-se o crescimento acelerado da demanda de ouro por parte da China, o que estimulou o aumento da cotação dos metais que, somado ao enfraquecimento do dólar, por sua vez está gerando uma maior procura por metais como reserva financeira (BARRETO, 2001).

${ }^{5}$ Ler mais em: http://basedatos.conflictosmineros.net/ocmal_db/, acesso em 11 nov 2017.
} 
A Possível Mineração no Bioma Pampa e o Escoamento de Minérios pelo Porto de Rio Grande | Sérgio Botton Barcellos, Caio Floriano dos Santos \& Ricardo Gonçalves Severo

socioambientais foram notificados no Brasil e destes 90 são conflitos oriundos de projetos e áreas de mineração, garimpos e siderurgia no Brasil.

No RS, após um ciclo intenso de atividades de silvicultura altamente impactantes para o bioma Pampa - que durou desde os anos 80 até os dias de hoje, com mais ênfase novamente a partir de 2004, ainda não findado -, os empreendimentos em mineração surgem como a mais nova promessa de "desenvolvimento econômico" e "emprego", com a proposta de "dinamizar" a economia desta região que é histórica e culturalmente agropastoril.

Sob essa perspectiva, após um ciclo intenso de atividades de silvicultura e a introdução da monocultura da soja altamente impactantes para o Bioma Pampa gaúcho, empreendimentos em mineração surgem como a mais nova promessa de "desenvolvimento econômico" e "emprego", com a proposta de "dinamizar" a matriz econômica, marcadamente pastoril. Mais especificamente a possibilidade da instalação de uma mina junto ao bioma Pampa está gerando impasses entre empresa, comunidade local ${ }^{6}$ e pesquisadores em debates e audiências públicas, assim como ações junto ao Ministério Público Federal (MPF) e Estadual (MPE). Mais recentemente, no município de Rio Grande, de forma inicial, há questionamentos de quais os riscos socioambientais caso toda essa produção seja escoada via Porto de Rio Grande, em especial do minério chumbo.

Assim, por meio desse trabalho, o nosso objetivo é apresentar um panorama e problematizar os principais aspectos relativos aos possiveis impactos socioambientais da instalação do "Projeto Caçapava do Sul" pelas empresas Votorantim Metais (Nexa) e a Iamgold Corporation. Após isso, iremos trazer à tona quais os riscos socioambientais para Rio Grande devido ao escoamento dos concentrados de minério de chumbo, cobre, etc, a partir dos casos de Antofagasta no Chile e Callao no Peru por tratarem de municipios portuários com características semelhantes.

\footnotetext{
6 Entende-se como comunidade: pequenos, médios e grandes produtores pecuários e agrícolas, quilombolas, indígenas e comunidades nos municípios.
} 
A Possível Mineração no Bioma Pampa e o Escoamento de Minérios pelo Porto de Rio Grande | Sérgio Botton Barcellos, Caio Floriano dos Santos \& Ricardo Gonçalves Severo

Ao discutir as relações de cooperação e conflito entre os atores nos debates públicos sobre a instalação desse empreendimento em mineração no bioma Pampa até o escoamento dos minérios pelo Porto de Rio Grande, buscaremos relacionar essa reflexão com a reconfiguração territorial do contexto rural brasileiro contemporâneo. O delineamento desses projetos, em vias de intensificação, e as configurações que emergem a partir desse novo contexto constitui um campo de pesquisa importante para as ciências sociais, em especial ao trazer o debate sobre os conflitos socioambientais que já estão se projetando e as manifestações políticas que têm se formado a partir disso.

\section{O projeto Caçapava do Sul no esteio dos conflitos socioambientais}

A partir dos anos 2000 na metade sul do RS, a região passou a ser alvo de novas investidas de grandes empreendimentos na busca de um almejado crescimento econômico de uma área considerada a parte menos "desenvolvida" do Estado. Assim, os cultivos de soja e milho transgênicos se propagaram sobre os campos nativos, ocasionando a multiplicação de espécies exóticas como o capim-anoni, lavouras de silvicultura (especialmente com eucaliptos, pinus e acácia negra) e, mais recentemente, as atividades em mineração estão na ordem do dia.

Com um grande potencial geológico, o governo brasileiro está estimulando a exploração das reservas minerais. No Plano Nacional de Mineração 20307, há previsão de investimentos de R\$ 350 bilhões até 2030, destinados prioritariamente à Amazônia, mas também a outros locais. De todo modo, trata-se de um indicativo de que poderá se intensificar esta atividade extrativa no país, inclusive em outros biomas, como o Bioma Pampa, que abrange parte do Brasil, no Rio Grande do Sul (RS), Uruguai e nordeste da Argentina. 
A Possível Mineração no Bioma Pampa e o Escoamento de Minérios pelo Porto de Rio Grande | Sérgio Botton Barcellos, Caio Floriano dos Santos \& Ricardo Gonçalves Severo

Em relação aos cultivos agropecuários, estas atividades se pautam na agricultura considerada "convencional" (com uso intenso de insumos e tecnologias externas), especialmente a sojicultura, atividades estas estimuladas por sucessivos governos de estado no RS e prefeituras na região, bem como por empresas ligadas ao agronegócio, que expandiram sua fronteira agrícola na metade sul do RS. Destaca-se que a perda de biodiversidade compromete o bioma, que já é o segundo mais alterado do Brasil, com apenas 36\% de cobertura original (MMA, 2017), o que pode levar à perda de espécies de fauna e flora, ao aumento da erosão do solo e do processo de arenização, assim como possíveis mudanças climáticas.

Outro importante estímulo governamental para a reconfiguração da territorialidade no Pampa decorreu no ano de 2005, quando o governador do estado do RS, na época Germano Rigotto, decidiu promover o "Projeto Losango"", voltado para a produção de silvicultura, na época, com investimento da empresa Votorantim, em forma de monocultura como mais uma promessa de um suposto crescimento econômico no Pampa gaúcho. Do ponto de vista socioeconômico, o objetivo seria transformar a matriz econômica do Pampa, que é histórica e culturalmente pastoril, em uma região de produção de madeira e celulose para hipoteticamente dinamizar a economia da região.

Nessa última década também foi observado nessa região, identificada geologicamente como Escudo Sul-Riograndense, o interesse pelas reservas de metal precioso, desde as jazidas já conhecidas e os antigos garimpos, até novas áreas com potencial, em municipios como Caçapava do Sul, Encruzilhada do Sul, Lavras do Sul, Santana da Boa Vista, São Sepé e Pinheiro Machado. Nestes municipios algumas áreas vêm sendo alvo, desde 2008, de um intenso trabalho de pesquisa geológica para detectar pontos promissores, ampliar as reservas existentes e viabilizar projetos de extração

\footnotetext{
8 Essa política pública estimulada por grandes empresas de produção de celulose e assumida pelo governo do RS na época dividia o estado em três áreas geridas por grandes empresas: a Aracruz (na Depressão Central e região de Porto Alegre), a Votorantim (na região do entorno e retaguarda das cidades de Pelotas e Rio Grande) e a StoraEnso (na fronteira sudoeste).
} 
A Possível Mineração no Bioma Pampa e o Escoamento de Minérios pelo Porto de Rio Grande | Sérgio Botton Barcellos, Caio Floriano dos Santos \& Ricardo Gonçalves Severo

mineral. Exemplo disso são os dados do Departamento Nacional de Produção Mineral (DNPM) - que passará a ser a Agência Nacional de Mineração $(\mathrm{ANM})^{9}$. Consta que há um cadastro de 162 processos ativos de prospecção para busca de ouro, chumbo, cobre, prata e zinco na região do Bioma Pampa (BARCELLOS, VAZ e PINHEIRO, 2018). Destaca-se, que de acordo com a ANM até o ano de 2015 o RS contava com 3.144 autorizações de pesquisas em 57 municípios; 946 requerimentos de pesquisa em 42 municipios; 295 concessões de lavra em 17 municípios e 2.051 processos de licenciamento em 62 municípios.

Em um periodo mais recente, em meados do ano de 2016, a Votorantim Metais Holding protocolou o Estudo de Impacto Ambiental - EIA e o Relatório de Impacto Ambiental - RIMA na Fundação Estadual de Proteção Ambiental (Fepam). Posteriormente a Fepam realizou duas Audiências Públicas para apresentar o projeto à população. Segundo o EIA do empreendimento (VOTORANTIM METAIS/GEOPROSPEC, 2016) a companhia tem feito pesquisas no local desde 2008 e teria confirmado a viabilidade econômica da extração de metais. De acordo com o sítio eletrônico 10 do empreendimento, neste projeto consta a intenção de exploração de zinco, cobre, chumbo, além de prata como subproduto, no Passo do Cação, localidade a cerca de cinco quilômetros de Minas do Camaquã. A proposta é exportar concentrados dos minérios pelo porto de Rio Grande para mercados internacionais como a Europa e a China, ou ainda aproveitar alguns deles nas metalúrgicas da Votorantim Metais em Minas Gerais (caso do zinco).

A empresa mineradora prevê um investimento inicial de $\mathrm{R} \$ 371$ milhões e anuncia que irá gerar 450 empregos diretos, com potencial de geração de empregos indiretos. O projeto está atualmente em análise do EIARIMA pela Fepam. A mineradora tinha expectativa de ter iniciado as

\footnotetext{
9Essa mudança de caráter institucional faz parte de um programa de revitalização da atividade mineradora estimulado pelo governo federal - responsável pela concessão de alvarás para o estudo de áreas e fiscalização de empresas, segundo o Portal Planalto (2017).

10 Ler mais em: <http:/ /www.projetocacapavadosul.com.br>.
} 
A Possível Mineração no Bioma Pampa e o Escoamento de Minérios pelo Porto de Rio Grande | Sérgio Botton Barcellos, Caio Floriano dos Santos \& Ricardo Gonçalves Severo

operações ao final de 2016, entretanto, com o conjunto das mobilizações, protestos e questionamentos ao EIA-RIMA, a data para o início está prevista pela empresa para o primeiro trimestre de 2020. A empresa afirma que não utilizará uma barragem de rejeitos líquidos. A extração das lavras prevê a produção anual de 16 mil toneladas de zinco concentrado, 5 mil de cobre e 36 mil de chumbo, durante 20 anos, que serão escoados para exportação pelo porto de Rio Grande.

Por outro lado, grupos organizados da sociedade civil (associações, universidades, prefeituras e grupos auto organizados) são contrários à instalação do empreendimento na região. Além da possivel contaminação do Rio Camaquã, em especial com o concentrado de chumbo, estas organizações ponderam que se houvesse um investimento maior na ovinocultura - a região possui mais de 650 mil cabeças de ovinos - seria possivel arrecadar mais de $\mathrm{R} \$ 120$ milhões.

Mediante este conflito de interesses e de projetos para a região, o EIARIMA apresentado pela empresa foi analisado com mais profundidade pela Fepam em novembro de 2016, época em que os grupos contrários ao empreendimento haviam realizado moções de repúdio e foram instaurados inquéritos nos ministérios públicos estadual e federal, reivindicando esclarecimentos sobre o processo junto à Fundação. Em janeiro de 2017, a Fepam concluiu parecer técnico com a análise do EIA-RIMA em que questiona a mineradora sobre diversos pontos, desde a descrição do empreendimento até complementações sobre o inventário feito na fauna da região. A empresa já solicitou vários prazos para organizar o cronograma de ações e ter maior sustentação técnica para se adequar às exigências e até dezembro de 2018 poderá haver uma resposta da Fepam (BARCELLOS, VAZ e PINHEIRO, 2018).

Eles também denunciam que a grande geração de empregos se dará fora da região, pois os minérios serão exportados na forma bruta via Porto de Rio Grande. Ou seja, a justificativa do empreendimento se instalar na região 
A Possível Mineração no Bioma Pampa e o Escoamento de Minérios pelo Porto de Rio Grande | Sérgio Botton Barcellos, Caio Floriano dos Santos \& Ricardo Gonçalves Severo

não seria nem econômica, nem social ou ambiental, mas é apenas voltada aos interesses econômicos da empresa.

Destaca-se que os atores que atuam na região do Bioma Pampa e se manifestaram publicamente de forma favorável, por enquanto, a instalação dos empreendimentos de mineração na região são: Nexa Resources (antes Votorantim); Águia Metais, governos municipais de Caçapava do Sul e Santana da Boa Vista; governo do estado do Rio Grande do Sul; alguns pesquisadores vinculados a Universidade Federal do Rio Grande do Sul (UFRGS) e Universidade Federal do Pampa (UNIPAMPA) vinculados ao curso de Geologia. Os atores que se manifestaram, até o momento, contrários a instalação dos empreendimentos minerários são: Associação para o Desenvolvimento do Alto Camaquã (ADAC); União pela Preservação (UPP); Comitê dos Povos e Comunidades Tradicionais do Pampa; Movimento pela Soberania Popular na Mineração (MAM); Comissão de Direitos Humanos e Comissão de Saúde e Meio Ambiente da Assembléia Legislativa do estado do RS; Comitê da Bacia Hidrográfica do Rio Camaquã; governos municipais de Bagé, Pinheiro Machado, Cristal, São Lourenço do Sul, Turuçu, Camaquã, Amaral Ferrador, Hulha Negra, Arambaré e Piratini; ONG - Amigos da Terra; diversos pesquisadores da FURG, UFPel, UFRGS, Universidade da Região da Campanha (URCAMP). Observa-se também a atuação do Ministério Público Estadual e Federal na escuta e na formulação de um parecer sobre a implantação do empreendimento (BARCELLOS, 2018).

Ao mesmo tempo, por parte de muitos moradores de Caçapava do Sul, em especial de Minas do Camaquã, e também dos moradores de Santana da Boa Vista, o posicionamento é favorável. Muitos alegam que além dos empregos e de aumentar a arrecadação do município com impostos, não há registros de problemas de saúde ocasionados pelo impacto dos empreendimentos de mineração que se instalaram ao longo dos anos na região. Entretanto, a diversos relatos sobre a contaminação de mercúrio no Rio Camaquã em 1989 e indícios de contaminação de solo (MAINO, 2010) e 
A Possível Mineração no Bioma Pampa e o Escoamento de Minérios pelo Porto de Rio Grande | Sérgio Botton Barcellos, Caio Floriano dos Santos \& Ricardo Gonçalves Severo

até da água por Cobre em volta das Minas do Camaquã (ALDROVALDI e PESTANA, 2012).

De acordo com Zhouri e Laschefski (2010) também entendemos que as situações consideradas como "problemas ambientais" originadas pelo "desenvolvimento" podem ser compreendidas pela noção de "conflito ambiental". O caráter conflituoso é relativo à forma como objetivamente são configuradas as relações entre os grupos com posições distintas, sobre pretensões de uso e significados atribuídos a um mesmo território em disputa e que são ecologicamente interconectados.

Os projetos desenvolvimentistas (como é o caso da mineradora) alteram uma dinâmica regional, impactando espaços físicos, ecossistemas terrestres e aquáticos e, principalmente, toda uma base de relações sociais que se manifestam nesse território. Essas alterações terão um maior impacto na alteração das relações sociais conforme as relações estabelecidas por essas populações com o ambiente físico e o meio biótico local, ou seja, se suas estratégias de existência e trabalhos estiverem relacionadas ao meio, essa condição estará ameaçada pela inserção do "empreendimento" (ACSELRAD e da SILVA, 2011).

Mediante este conflito de interesses e de projetos para a região, o EIA e o RIMA apresentado pela empresa foi analisado com mais profundidade pela Fepam em novembro de 2016, época em que os grupos contrários ao empreendimento haviam realizado moções de repúdio e foram instaurados inquéritos nos Ministérios Públicos Estadual e Federal, reivindicando esclarecimentos sobre o processo junto à Fundação. Em janeiro de 2017, a Fepam concluiu parecer técnico com a análise do EIA-RIMA em que questiona a mineradora sobre diversos pontos, desde a descrição do empreendimento até complementações sobre o inventário feito na fauna da região. A empresa já solicitou vários prazos para organizar o cronograma de ações e ter maior sustentação técnica para se adequar às exigências (BARCELLOS, VAZ e PINHEIRO, 2018). 
A Possível Mineração no Bioma Pampa e o Escoamento de Minérios pelo Porto de Rio Grande | Sérgio Botton Barcellos, Caio Floriano dos Santos \& Ricardo Gonçalves Severo

Diante desse impasse relativo à instalação do empreendimento, "os conflitos ambientais surgem das distintas práticas de apropriação técnica, social e cultural do mundo material" (ZHOURI; LASCHEFSKI, 2010, p. 17). Ao mesmo tempo, sob uma perspectiva mais ampla, podemos compreender esse conflito em meio a um cenário marcado por politicas econômicas de ajuste fiscal e pela formação de superávits comerciais, no qual os instrumentos normativos de regulação ambiental estão no cerne de uma disputa. Essa questão posiciona, de um lado, aqueles que consideram os trâmites e as consultas às comunidades como "obstáculos ao desenvolvimento", de outro, os atores que querem participar das decisões sobre os territórios onde vivem e constroem os seus projetos de vida.

De acordo com Guedes (2014) neste contexto, a atividade mineral é percebida como invasiva e ameaçadora à qualidade de vida de povos e populações. O processo de licenciamento para se instalar, operar e produzir atividades de mineração no Brasil a cada dia são formulados e reformulados para favorecer os empreendedores. As duas licenças exigidas, a licença para minerar e a licença ambiental, realizam-se em âmbito administrativo e as populações das localidades afetadas não têm poder de veto. As legislações no Brasil não garantem à proteção de direitos sociais das populações em relação a empreendimentos de mineração e são calcadas em instrumentos mitigatórios e compensatórios.

\section{Rio Grande como zona de sacrifício ambiental e os grandes empreendimentos em mineração no Rio Grande do Sul}

O município de Rio Grande é o mais antigo do estado, atualmente é palco de diversos investimentos públicos e privados. Localizado na planície costeira, tendo como limites ao norte, a cidade de Pelotas e Laguna dos Patos; ao sul Santa Vitória do Palmar; a leste o Oceano Atlântico e a Lagoa dos patos; e a oeste Pelotas, Arroio Grande e Lagoa Mirim e atualmente possui aproximadamente 205 mil habitantes (IBGE, 2016). Entretanto, esses empreendimentos geraram impactos socioambientais negativos no município 
A Possível Mineração no Bioma Pampa e o Escoamento de Minérios pelo Porto de Rio Grande | Sérgio Botton Barcellos, Caio Floriano dos Santos \& Ricardo Gonçalves Severo

como um todo e, mais diretamente, nos bairros estabelecidos ao redor da área portuária, como Bairro Getúlio Vargas, Santa Tereza, Mangueira, Barra Nova, Barra Velha e Barraquinhas, essa última removida em virtude da construção do Dique Seco do atual Estaleiro Rio Grande e ampliação do cais da BUNGE alimentos (SANTOS, 2016).

Diante disso, registra-se que desde 2003 ocorrem investimentos expressivos junto ao setor naval brasileiro. Foram constituídas políticas de revitalização da indústria naval no país que, posteriormente, passaram a integrar o Programa de Aceleração do Crescimento (PAC). O investimento e aporte dado ao setor pelo governo federal geraram transformações significativas em questões sociais, ambientais e econômicas. As politicas de ampliação e modernização do complexo portuário do Rio Grande se estendem, na atualidade, para além do município litorâneo, sendo denominado como Polo Naval (CHAGAS, 2014).

Esse processo de reestruturação do Polo Naval e de investimentos no municipio e região a partir do PAC podem ser observados sob uma perspectiva de um processo histórico, contraditório, disputado e permeado por conflitos entre os diversos atores que atuam no espaço social e nos conflitos socioambientais em Rio Grande. Assim, considera-se que essa contradição que ocorre em meio ao processo de acumulação capitalista tende a transgredir o limite das condições naturais em um ecossistema. De acordo com Santos e Machado (2013) o município pode ser caracterizado como zona de sacrifício ambiental, por ter em seu território inúmeras atividades com alto potencial poluidor (indústria de fertilizantes, refinaria de petróleo, armazenamento de granéis químicos e outras).

O Porto do Rio Grande é um dos principais portos brasileiro da região Sul em movimentação portuária. Sua área de influência geográfica se estende ao Estado de Santa Catarina e aos países vizinhos: Argentina, Paraguai e Uruguai, o que faz com que seja conhecido e chamado como Porto do MERCOSUL. Exporta e movimenta uma grande diversidade de 
A Possível Mineração no Bioma Pampa e o Escoamento de Minérios pelo Porto de Rio Grande | Sérgio Botton Barcellos, Caio Floriano dos Santos \& Ricardo Gonçalves Severo

cargas, com destaque para: soja, fertilizantes, peças de madeira e outras (BARCELLOS E SILVA, 2017).

Entretanto, cabe considerar que a questão ambiental nessa região também se expressa de modo importante e como componente essencial na constituição desse espaço social, devido à localização do município junto ao Estuário da Laguna dos Patos e da Praia do Cassino, no Oceano Atlântico. Assim, a sua importância também em termos de biodiversidade está destacada, ao mesmo tempo em que, a expansão e reconfiguração criam tensões e (re) criam relações de conflito e contradições no que tange à capacidade de suporte ambiental desse ecossistema.

Em relação aos impactos socioambientais, a mineração gera disputas acerca de bens comuns, como o patrimônio cultural e histórico, o solo, o ar e água, pois tende a modificar o ambiente radicalmente em diversos casos. Mesmo considerando que há risco para a atividade econômica, em especial sobre o retorno de lucro, tais atividades tendem a desconsiderar os danos que via de regra causam às populações do entorno nos territórios em que seus empreendimentos são realizados, ignorando, portanto, riscos socioambientais. Assim, é compreensível que a lógica destas empresas elimine a consulta e participação das comunidades locais sobre a decisão de instalação desses empreendimentos e o respeito aos arranjos territoriais, as formas de vida e projetos locais de desenvolvimento ${ }^{11}$.

Um exemplo histórico, demonstrativo disso, é que em 1970, o Distrito Industrial foi construído sem a realização de um EIA, já que naquela época não existia legislação sobre o Licenciamento Ambiental ${ }^{12}$. Paradoxalmente, a Licença de Operação do Distrito Industrial do Rio Grande (DIRG) somente foi liberada em 2008 pela Fepam. Foi neste contexto que se possibilitou que o Distrito Industrial fosse instalado sobre uma região de dunas, mariscais e

\footnotetext{
11 Para Chagas (2014) a acumulação do capital na região do Extremo Sul é alicerçada na dependência externa e na segregação social. Em todos os períodos é evidente a presença do capital exógeno à cidade, fruto de ordenações espaço-temporais sistêmicas atraídas fundamentalmente pelo porto existente e de intervenções estatais na economia local.

12 Em ambos os casos o EIA foi elaborado pelo corpo técnico da Fundação Universidade Rio Grande (FURG) / Laboratório de Gerenciamento Costeiro (SANTOS, 2016; BARCELLOS e SILVA, 2017).
} 
A Possível Mineração no Bioma Pampa e o Escoamento de Minérios pelo Porto de Rio Grande | Sérgio Botton Barcellos, Caio Floriano dos Santos \& Ricardo Gonçalves Severo

banhados que foram progressivamente aterrados modificando o seu conteúdo paisagístico (BARCELLOS e SILVA, 2017). O Porto do Rio Grande teve sua Licença Ambiental de Operação no ano de 1997, expedida pelo IBAMA após uma denúncia de crime ambiental, destaca-se que desde então as condicionantes $\mathrm{e}$ as medidas mitigadoras são descumpridas pela Superintendência do Porto do Rio Grande (SANTOS, 2016).

Dessa forma, caso o Projeto Caçapava do Sul seja implementado, é pelo Porto de Rio Grande que escoará o concentrado de minérios metálicos, inclusive o metal pesado Chumbo com alta capacidade de contaminação (em especial em crianças). Alerta-se que a comunidade não foi consultada ou, ao menos informada, antes da Audiência Pública, promovida em junho de $2017^{13}$, sobre a possibilidade da instalação desse empreendimento oferecer riscos de contaminação a população e ao ambiente pela aspersão de partículas de minérios no ar e na água. Destaca-se, que diversos municípios que compõem a bacia hidrográfica do Rio Camaquã também não foram consultados ou informados dos riscos socioambientais que esse empreendimento oferece, seja pela possibilidade de contaminar as águas do Rio Camaquã,pela dispersão de partículas pelo trajeto dos caminhões que transportarão os concentrados até o Porto de Rio Grande.

Cabe, ainda, destacar que o Porto do Rio Grande é a porta de saída desses processos de mineração, em prospecção ou licenciados, como é o caso da exploração de Zircônio, Ilmenita e Rutilo pela Rio Grande Mineração - RGM, no município de São José do Norte, que recentemente recebeu a Licença Ambiental Prévia do IBAMA, mesmo com a comunidade se manifestando de forma contrária.

A necessidade de se realizar tal discussão sobre tal processo é de suma importância, ainda mais se pensarmos que Rio Grande é "antes de tudo um porto", sendo o mesmo gerido de forma autônoma e independente ao planejamento do município (SANTOS, 2016). Além da necessidade de

\footnotetext{
13 Audiência promovida pela Câmara de Vereadores de Rio Grande através do mandato da Vereadora Denise com apoio de docente da FURG - Campus Carreiros. Disponivel em: https://www.youtube.com/watch?v=FWSSmq31xb4
} 
A Possível Mineração no Bioma Pampa e o Escoamento de Minérios pelo Porto de Rio Grande | Sérgio Botton Barcellos, Caio Floriano dos Santos \& Ricardo Gonçalves Severo

debates com a comunidade, chama-se a atenção que a dimensão ambiental é constituida por bens naturais, e não apenas por recursos naturais a serem explorados economicamente, a dimensão cultural é parte de um patrimônio cultural material e imaterial que mobiliza histórias, afetos. Isto é, com a instalação destes "empreendimentos" de mineração com seus impactos e riscos de fortes danos que podem alterar profundamente um território e isso mobiliza e põe em jogo um conjunto de valores, costumes e formas de vida para além de uma dimensão estritamente econômica.

\section{Os casos de Antofagasta, no Chile, e Callao, no Peru, como demonstrativos do risco para Rio Grande}

Antofagasta é a capital da provincia de mesmo nome no Chile. Tem cerca de 300 mil habitantes e é o quinto maior município do país. Ao longo da sua história, Antofagasta caracteriza-se pelo transporte de diversas mercadorias, devido a atividade portuária que é datada desde o século XIX. Desde os anos 1980 são registrados conflitos socioambientais no município devido à constatação de contaminação ambiental e da população por minérios metálicos como chumbo, cobre e outros minerais. A principal empresa que está sendo apontada, pela comunidade local, como causadora da contaminação é a Antofagasta Terminal Internacional (ATI).

Um exemplo mais recente disso, é que em dezembro de 2014, o Instituto de Saúde Pública (ISP) realizou amostras de sangue de 107 crianças pertencentes aos jardins "Semillita" e "pintos", localizado perto do porto, dos quais 36 deles tiveram arsênico e chumbo detectados no sangue. Destas, cinco crianças tinham menos do que $10 \mathrm{ug} / \mathrm{dl}$ de chumbo, setenta e nove entre 10 e $45 \mathrm{ug} / \mathrm{dl}$, quatro entre 45 e $60 \mathrm{ug} / \mathrm{dl}$, e onze acima de 60 ug / dl. Em 26 de Janeiro Hospital Regional Pediátrica Unidade Antofagasta anunciou novos resultados de teste para o berçário, em que de 99 amostras, 94 tinham niveis de chumbo acima da norma estabelecida (MUÑOZ, 2016). 
A Possível Mineração no Bioma Pampa e o Escoamento de Minérios pelo Porto de Rio Grande | Sérgio Botton Barcellos, Caio Floriano dos Santos \& Ricardo Gonçalves Severo

Além disso, a Medical College do Chile naquele ano encontrou 19 metais pesados no ar de Antofagasta, onde, de acordo com especialistas, os números são cinco vezes maiores que o permitido pelo padrão chileno. Embora não haja nenhuma norma regulamentar sobre metais no solo no Chile, nos Estados Unidos e na Europa mais de $400 \mathrm{mg} / \mathrm{kg}$ de chumbo e $20 \mathrm{mg} / \mathrm{kg}$ de arsénico é considerado nocivo para a população ${ }^{14}$ (VERGARA, 2015).

Não há consenso científico de como ocorrem as contaminações, entretanto, de acordo com relato dos pesquisadores do ISP os locais de embarque e desembarque dos minérios metálicos coincidem com as amostras de contaminantes encontradas na orla maritima de Antofagasta (MUÑOZ, 2016).

O município de Callao no Peru é outro caso que nos remete a reflexão e onde é possivel perceber possiveis semelhanças com o que pode vir a ocorrer em Rio Grande com a carga e descarga cotidiana de concentrado de minérios metálicos no Porto, como por exemplo, o Chumbo. Callao é o terceiro maior município do Peru com mais de 800 mil habitantes. A cidade registra atividades portuárias no oceano pacífico desde o século XVI. No porto de Callao, de acordo com estatísticas da Direção Geral de Minas do Ministério de Minas e Energia do Peru são exportadas mais de 200.000 toneladas/ano de minérios. Desses minérios transportados a maioria é Zinco $(45 \%)$, cobre $(40 \%)$ e chumbo (14\%). Mesmos minérios prospectados para o projeto Caçapava do Sul.

Desde 2005 há denúncias por contaminação de crianças por chumbo na região. Há mais recente, no ano de 2016, de acordo com o Jornal "El Comercio"15, ocorreram 90 casos de crianças menores de 12 anos com alto teor de chumbo no sangue de acordo com as autoridades em saúde no

\footnotetext{
14 De acordo com Muñoz, o ISP, numa análise em abril de poeira perto do terminal em diferentes pontos, ele descobriu que 5 metais tinham um alto nivel pesquisados. Estes são de cobre (maior valor 46898,1 mg/ kg), zinco (30545,7 mg / kg), arsénio (1492,1 mg / kg), cádmio (129,7 mg / kg) e chumbo (3698, $4 \mathrm{mg} / \mathrm{kg})$.

15 Ler mais em: http://elcomercio.pe/peru/callao/callao-90-ninos-sufren-alta-contaminacion-plomo$\underline{276470}$
} 
A Possível Mineração no Bioma Pampa e o Escoamento de Minérios pelo Porto de Rio Grande | Sérgio Botton Barcellos, Caio Floriano dos Santos \& Ricardo Gonçalves Severo

distrito de Mi Peru em Callao. Segundo o diretor regional de saúde 338 crianças foram atendidas com sintomas de contaminação por chumbo, sendo que 73\%, com idade entre 2 a 12 anos, apresentam nível de contaminação tolerável ou categoria I (menos de $10 \mathrm{ug} / \mathrm{dl}$ ), mas 25\% têm a Categoria II (10 a 20 ug / dl) e 3\% mais de 20 ug / dl de sangue.

Para as autoridades de Callao estes números são resultado da contaminação ocasionada por metais pesados extraídos por empresas que operam ao norte e nas proximidades de Mi Peru. A empresa que realiza o transporte e desembarque dos minérios dos trens e caminhões e embarque dos mesmos no Porto é a Transportadora delCallao ${ }^{16}$. Os clientes dessa transportadora incluem grandes empresas de mineração que operam na região central do Peru. Dentre estas a própria empresa menciona a Chinalco, Volcan, Glencore, Milpo (no qual a Votorantim é a principal acionista) ${ }^{17}$, El Brocal, etc.

Elencamos o trabalho de Lisboa (2016) para descrever quais os possiveis danos à saúde decorrentes da contaminação por chumbo em humanos. Essa pesquisa foi desenvolvida em Antofagasta e as crianças foram os sujeitos da pesquisa. Destacamos o chumbo, pois no caso do conflito em relação ao empreendimento a ser instalado na região do Bioma Pampa é um dos minérios mais em evidência nos debates sobre o seu risco de contaminação humana, animal e ambiental.

Em relação ao chumbo inorgânico, que é o formato em que se encontra o minério na forma de concentrado, quando ele causa intoxicação pode causar inicialmente os seguintes sintomas: fraqueza, cansaço fácil, sonolência irritabilidade e nervosismo. Na evolução do quadro clínico para uma fase crônica de intoxicação os sintomas podem ser os seguintes: dores abdominais em cólica, constipação, impotência sexual, palidez cutânea, anemia, hipertensão arterial, insuficiência renal e neuropatia periférica. As crianças são mais susceptíveis devido ao consumo por quilo de peso,

16 Ler mais em: http://gestion.pe/empresas/faja-minerales-callao-sumara-tres-millones-toneladasembarcadas-su-primer-ano-operaciones-2130536

17 Mais informações em: http://www.milpo.com/ 
A Possível Mineração no Bioma Pampa e o Escoamento de Minérios pelo Porto de Rio Grande | Sérgio Botton Barcellos, Caio Floriano dos Santos \& Ricardo Gonçalves Severo

geralmente por estarem mais expostos a terra e a objetos e também por seus órgãos não estarem plenamente desenvolvidos, quantidades pequenas do metal podem causar distúrbios psicológicos. Desse modo, no caso de contaminações por chumbo no Chile a contaminação também está causando déficit de Quociente de Inteligência (QI) em crianças (LISBOA, 2016).

Diante destes casos expostos, chamamos a atenção para possiveis semelhanças dos dois casos com o município de Rio Grande no que tange a atividade portuária e a possibilidade de nela ocorrer o embarque e transporte de concentrado de minérios metálicos como chumbo e cobre, bem como, caso isso aconteça, os possiveis riscos que a mesma oferece à saúde da população e ao ecossistema do município e da região. Percebe-se que a atividade mineral na América Latina e no Brasil é considerada invasiva e ameaçadora à qualidade de vida de povos e populações.

Diante, dessa possibilidade é que no nosso entendimento o município de Rio Grande será área de influência direta desse empreendimento viemos solicitar que o MPF observando suas prerrogativas solicite a realização de Audiência Pública (AP), uma vez que essa até o presente momento não foi realizada. Entendemos, que essas APs serviram para informação e consulta da comunidade riograndina por parte do empreendimento e das instituições do poder público diretamente responsáveis por isso, por exemplo, a FEPAM no RS.

De acordo com Leal (2014) com a possivel instalação dos empreendimentos de mineração pelo Brasil são anunciadas propostas de criação de empregos, melhorias nas condições de vida, dinamização da economia e 'crescimento'. Contrastando com esse discurso, que comumente acompanha a instalação de empreendimentos em mineração, um pouco depois chegam os impactos ambientais, como ocorreram nos exemplos descritos sobre o Chile e o Peru, a poluição; adoecimento da população; alteração de paisagens, biomas e modos de vida das comunidades impactadas; remoções; contaminação dos mananciais hídricos; assoreamento; inchaço populacional durante o período de obras, aumento 
A Possível Mineração no Bioma Pampa e o Escoamento de Minérios pelo Porto de Rio Grande | Sérgio Botton Barcellos, Caio Floriano dos Santos \& Ricardo Gonçalves Severo

da especulação imobiliária; sobrecarregamento dos aparelhos públicos de saúde, saneamento etc; denúncias de trabalho irregular, entre outros (LEAL, 2014).

\section{Considerações finais}

De acordo com a discussão realizada por Almeida (2007) há certa reedição de práticas instituídas desde o período colonial no Brasil que mantém uma estreita relação entre a extração de recursos naturaise a conformação mercantil. Os problemas locais, contudo, são globais: são problemas que dizem respeito a paisagens naturais (mares, florestas, savanas, rios) e aqueles que os disputam, como organizações e movimentos sociais, agências do Estado, megaempresas. Provavelmente, em 2019, haverá uma resposta sobre a instalação do empreendimento Caçapava do Sul no RS e por isso se faz necessário refletir sobre as consequências dessas disputas para o futuro daquele território.

Ao mesmo tempo, compreendemos essas disputas e conflitos socioambientais entre atores "contrários" e "a favor" da instalação deste empreendimento minerário no RS e outros demais que também almejam se instalar como uma forma de atuação de grupos transnacionais com apoio de grupos nacionais, configurando um processo de avanço de fronteiras de exploração natural, precarização das condições de trabalho para a formação de superávits comerciais e de dominação territorial para catalisar processos de acúmulo de capital político e econômico. Em meio a isso, a reformulação ou "flexibilização" destes instrumentos normativos de regulação ambiental estão no cerne de uma disputa. Assim, de acordo com Almeida (2012, p. 63), está em jogo um reordenamento territorial, operado também pelo Estado brasileiro, "voltada para a reestruturação de mercados, disciplinando a comercialização da terra e dos recursos florestais e do subsolo", expresso em incentivos e flexibilizações de leis de proteção ambiental e social em curso.

Trata-se, segundo o autor, não mais de proteção (em sentido conservacionista), mas sim, em direção diametralmente oposta (mesmo que 
A Possível Mineração no Bioma Pampa e o Escoamento de Minérios pelo Porto de Rio Grande | Sérgio Botton Barcellos, Caio Floriano dos Santos \& Ricardo Gonçalves Severo

não haja alterações retóricas profundas), de "protecionismo", calcado na possibilidade de intensificação do uso de recursos naturais a partir daquilo que é indicado como potencial de crescimento econômico. Nesse processo, observa-se que as monoculturas agrícolas junto com empreendimentos hidrelétricos, projetos de mineração, entre outros, estão progressivamente crescendo no Brasil, como a promessa de "solução" para regiões "pobres" e “pouco desenvolvidas".

Mesmo considerando que há risco nesta atividade econômica, em especial sobre o retorno de lucro, tais atividades tendem a desconsiderar os danos que causam às populações nos territórios em que os empreendimentos são realizados, ignorando, portanto, os impactos socioambientais causados. A mineração gera disputas acerca de bens comuns, como o patrimônio cultural e histórico, o solo, o ar e água, pois tende a modificar o ambiente radicalmente em diversos casos, inclusive no caso de uma parcela do Bioma Pampa na metade sul do RS entre Caçapava do Sul até o Porto de Rio Grande.

Ressalta-se, que e a comunidade riograndina não foi consultada ou ao menos informada, antes de uma Audiência informativa promovida em junho de $2017^{18}$, sobre a possibilidade da instalação desse empreendimento e que essa atividade pode oferecer riscos de contaminação a população e ao ambiente pela aspersão de partículas de minérios no ar e na água, além de em caso de vazamento de rejeitos no Rio Camaquã afetar a Lagoa dos Patos e a porção do Oceano Atlântico em Rio Grande. Cabe destacar que essa Audiência Pública foi promovida de forma autônoma ao processo de licenciamento ambiental por pesquisadores da Universidade Federal do Rio Grande (FURG) e o gabinete de uma única vereadora que acolheu a pauta.

Destaca-se ainda que diversos municipios que compõem a bacia hidrográfica desse rio também não foram consultados ou informados dos riscos socioambientais que esse empreendimento oferece, seja pela

\footnotetext{
18 Audiência promovida pela Câmara de Vereadores de Rio Grande através do mandato da Vereadora Denise com apoio de docente da FURG - Campus Carreiros. Disponível em: https://www.youtube.com/watch?v=FWSSmq31xb4
} 
A Possível Mineração no Bioma Pampa e o Escoamento de Minérios pelo Porto de Rio Grande | Sérgio Botton Barcellos, Caio Floriano dos Santos \& Ricardo Gonçalves Severo

possibilidade de contaminar as águas do Rio Camaquã que deságua em Rio Grande, seja pela aspersão de partículas dos concentrados durante o trajeto rodoviário até a descarga dos caminhões e carregamento dos navios no Porto de Rio Grande. Também cabe considerar a grande possibilidade de contaminação no armazenamento na área retroportuária e no processo de embarque dos minérios já descritos anteriormente.

Compreendemos essas disputas e conflitos socioambientais entre atores "contrários" e "a favor" da instalação deste empreendimento minerário no RS e outros demais que também almejam se instalar como uma forma de atuação de grupos transnacionais com apoio de grupos nacionais, configurando um processo de avanço de fronteiras de exploração natural, precarização das condições de trabalho para a formação de superávits comerciais e de dominação territorial para catalisar processos de acúmulo de capital político e econômico. Em meio a isso, a reformulação ou "flexibilização" destes instrumentos normativos de regulação ambiental estão no cerne de uma disputa. Mesmo considerando que há risco nesta atividade econômica, em especial sobre o retorno de lucro, tais atividades tendem a desconsiderar os danos que causam às populações nos territórios em que os empreendimentos são realizados, ignorando, portanto, os impactos socioambientais causados.

Por fim, mas apenas iniciando outras possibilidades, não há uma definitiva compreensão acadêmica acerca da problemática apresentada nesse trabalho. Esse ensaio, além de ser mais um elemento de pesquisa e de formação acadêmica constante, tem limitações que ao longo do processo de investigação serão ampliadas e discussões que serão aprimoradas. Além disso, busca-se deixar em aberto outras questões e possibilidades de pesquisa para os (as) demais pesquisadores (as) do tema e da região onde está ocorrendo essa disputa acerca de diferentes formas e projetos de vida no Bioma Pampa gaúcho.

\section{Referências}




\section{ALDROVANDI, P.; PESTANA, M. H. D. Avaliação da contaminação por} metais na área das Minas do Camaquã. Salão da UFRGS, 2012.

ALMEIDA, A. W. B. de. Territórios e territorialidades específicas na Amazônia: entre a "proteção" e o "protecionismo". Cad. CRH, Salvador, v. 25, n. 64, p. 63-72, Apr. 2012. Disponivel em: $<$ http:/ / www.scielo.br/scielo.php?script=sci_arttext\&pid=S0103$49792012000100005 \& l n g=e n \& n r m=i s o>$. Acessado em 13/10/2017.

ALMEIDA, M.W.B. Narrativas agrárias e a morte do campesinato. RURIS, v.1, n.2, p. 157-188. 2007.

ACSELRAD, H; DA SILVA, M. G. Rearticulações sociais da terra e do trabalho em áreas de grandes projetos hidrelétricos na Amazônia - o caso de Tucuruí. p. 61-92 In: ZHOURI, A. (Org.). As Tensões do lugar hidrelétricas, sujeitos e licenciamento ambiental. Belo Horizonte: EdUFMG, 2011.

BARCELlOS, Sergio Botton; SILVA, Raquel Hadrich. Perspectivas de análise socioambiental: entre os projetos de "desenvolvimento" e o cotidiano da pesca. In: Santos, Caio Floriano; Machado, Carlos RS; Barcellos, Sergio Botton. Conflitos ambientais e Urbanos: pesquisas e resistências. Rio Grande: Editora da Furg. 2017 (no prelo)

BARCELLOS, Sérgio B. VAZ, Daniel; PINHEIRO, Patrícia dos Santos. Os debates sobre a mineração no Bioma Pampa: conflitos socioambientais em meio a projetos locais de vida. Revista Novos Cadernos Amazônicos. UFPA. 2018. (no prelo)

BARCELLOS, Sérgio Botton. A reconfiguração territorial do Pampa Gaúcho em meio aos conflitos socioambientais de mineração. In: 42. Encontro Nacional da ANPOCS, 2018, Caxambu - MG. Anais do $42^{\circ}$ Encontro Anual da Anpocs. São Paulo - SP: ANPOCS, 2018.

BRASIL, Ministério de Minas e Energia. Plano Nacional de Mineração 2030 (PNM - 2030). Brasília: MME, 2010.

CHAGAS, P. B. Desenvolvimento e dependência no Brasil: reflexos do Programa de Aceleração do Crescimento (PAC) no município do Rio Grande (RS). Tese de Doutorado. Programa de Pós-Graduação em Administração/UFRGS. 2014.

GUEDES, Jefferson. Exploração de minério de ferro em Conceição do Mato Dentro (MG) afeta meio social e ambiente. In: FERNANDES, Francisco Rego Chaves; ALAMINO, Renata de Carvalho Jimenez; ARAUJO, Eliane Rocha (Eds). (2014). Recursos Minerais e Comunidade: impactos humanos, socioambientais e econômicos. Rio de Janeiro, CETEM/MCTI. 2014. 
A Possível Mineração no Bioma Pampa e o Escoamento de Minérios pelo Porto de Rio Grande | Sérgio Botton Barcellos, Caio Floriano dos Santos \& Ricardo Gonçalves Severo

IBGE, Cidades @. Disponivel em: http://www.cidades.ibge.gov.br/xtras/perfil.php?lang=\&codmun=431560\&s earch=rio. Acessado em: 28 de junho de 2017.

IPEA. Ressurgimento da indústria naval no Brasil: (2000-2013) / editores: Carlos Alvares da Silva Campos Neto, Fabiano MezadrePompermayer. Brasília: Ipea, 2014.

FILIPPI, E. E. (Org.) Rio Grande do Sul 2000-2010/ - São Paulo: Editora Fundação Perseu Abramo, 2014.

LEAL, Leila. Mineração: o rastro do desenvolvimento e conflitos territoriais no Brasil.2014. Disponivel em: http://www.epsjv.fiocruz.br/noticias/reportagem/mineracao-o-rastro-dodesenvolvimento-e-conflitos-territoriais-no-brasil. Acesso em: 13 ago. 2018.

LISBOA, Loreto et al . Proximityofresidencetoanold mineral storage site in Chile andblood lead levels in children. Cad. Saúde Pública, Rio de Janeiro, v. 32, n. 4, 2016.

MAINO, Jeferson de Mello; WINTER, Stefanie Kohn; NOVAES, Luis Eduardo Silveira da Mota. Impactos sócio-ambientais causados pela deposição de rejeitos de mineração na localidade de Minas do Camaquã, Caçapava do Sul/RS, 2006. Disponivel em:

http: / / www.ufpel.edu.br/cic/2006/arquivos/CH_00478.rtf. Acesso em: 22 out. 2010.

MALERBA, J. (Org.). Novo Marco Legal da mineração no Brasil: Para quê? Para quem?. Rio de Janeiro: FASE, 2012. Disponivel em: http://www.fase.org.br/v2/pagina.php?id=3793

MUÑOZ

Gabriela.

Alarmantes

niveles

de contaminaciónponenenriesgolasalud de niños de Antofagasta. Jornal Nacional. Chile. Publicado em 18 de maio de 2016. Disponivel em: http://www.biobiochile.cl/noticias/2016/05/18/estudio-advierte-

alarmantes-indices-de-contaminacion-en-establecimientos-de-

antofagasta.shtml

Acessado em: 28 de maio de 2017.

SANTOS, C. F.; MACHADO, C. RS. Extremo Sul do Brasil - uma grande "zona de sacrificio". In: MACHADO, C. RS; SANTOS, C. F.; ARAÚJO, C. F.; PASSOS, W. V. (Orgs). Conflitos Ambientais e Urbanos: debates, lutas e desafios. Porto Alegre: Evangraf. 2013.

SANTOS, Caio Floriano. O porto e a desigualdade ambiental em Rio Grande (RS/Brasil) : a educação ambiental na gestão "empresarial dos riscos sociais" e "social do território". Tese de doutorado no Programa de 
A Possível Mineração no Bioma Pampa e o Escoamento de Minérios pelo Porto de Rio Grande | Sérgio Botton Barcellos, Caio Floriano dos Santos \& Ricardo Gonçalves Severo

Pós-Graduação em Educação Ambiental (PPGEA/FURG), 2016. Disponivel em:https://argo.furg.br/? BDTD11131 . Acessada em: 05/07/2017.

VERGARA, Paula. Contaminación de arsénico y plomo: Unconflicto que creceenAntofagasta. Site Cooperativa.cl.Chile.Disponivel em: http:/ / www.cooperativa.cl/noticias/pais/region-deantofagasta/contaminacion-plomo/contaminacion-de-arsenico-y-plomo-unconflicto-que-crece-en-antofagasta/2015-02-04/140741.html.Acessado em: 27 de maio de 2017.

VOTORANTIM METAIS/GEOPROSPEC. Estudo de Impacto Ambiental (EIA): Projeto Caçapava do Sul. Volume 1 a 4. Caçapava do Sul - RS. Geoprospec Geologia e Projetos Ambientais LTDA. 2016. Disponivel em: http://www.projetocacapavadosul.com.br/\#vmetais >, acesso em 03 de março de 2017.

ZHOURI, A.; LASCHEFSKI, K. (org.) Desenvolvimento e Conflitos ambientais. Belo Horizonte: Editora UFMG, 2010. 